\title{
Proyectos 5, reformulación del trabajo y refuerzo de la participación del estudiante mediante las actividades de contraste.
}

\section{Architectural Design 5, reformulating the work and intensifying student's participation with contrast activities.}

ZACARÍAS DE JORGE-CRESPO

ORCID: https://orcid.org/0000-0002-1208-5393

Universidad de Sevilla

Escuela Técnica Superior de Arquitectura

Departamento de Proyectos Arquitectónicos

zacarias@us.es

DOI: http://dx.doi.org/10.12795/9788447231003.036

Pp.: 753-776 


\section{Introducción}

Las adaptaciones del plan de estudios a los principios de Bolonia han supuesto cambios fundamentales en el desarrollo de la actividad docente y sus tiempos en las asignaturas troncales adscritas a la docencia del Departamento de Proyectos Arquitectónicos. Aplicado sobre Proyectos 5 , en este curso de formación e innovación docente ha sido posible afrontar el reto de la reorganización del trabajo en el aula. En el planteamiento propuesto para la implementación del Ciclo de Mejora en el Aula se considera el cambio de papel que debe tener el estudiante en su propia formación. En la posición de partida en esta asignatura, los estudiantes tienen un papel relevante al abordar el aprendizaje personal de manera autónoma. En la resolución del ejercicio del curso llegarán tan lejos como cada uno quiera. Se trabaja en responder las preguntas encadenadas de cualquier proyecto, iniciándose en el planteamiento, continuando en la fase de proyecto y, por último, imaginando cómo se construirá. La propuesta se aproxima a las ideas de mirar, pensar y crear desde el campo disciplinar del proyecto con las tres actividades de contraste. Se pondrá en valor el resultado colectivo a partir de la resolución individual de las tareas en el inicio del ejercicio de curso. También se presta atención a la formación crítica de los estudiantes, expresándola con la justificación de sus decisiones a partir de las acciones de observación, pensamiento y creación desarrolladas.

\section{Contexto}

La proyección de este trabajo en el aula se realiza sobre la asignatura de Proyectos 5, que se imparte en el primer cuatrimestre del tercer curso del Grado en Fundamentos de Arquitectura. Esta asignatura tiene continuidad en el segundo cuatrimestre con Proyectos 6 . Ambas son troncales y tienen seis créditos cada una. Como criterio general

Ciclos de Mejora en el Aula (2020). Experiencias de Innovación Docente de la US Esta obra se distribuye con la licencia Creative Commons 
del Departamento en la asignación docente, cada profesor imparte un curso completo, es decir, las dos asignaturas al mismo grupo de estudiantes. Otra condición reseñable en el desarrollo de la docencia es la libertad de actuación de cada profesor en su grupo para el diseño y desarrollo de las actividades de la asignatura. En la asignación del horario, las cuatro horas se imparten un día a la semana, en dos sesiones de dos horas. El grupo suele ser de 27 a 32 estudiantes, dependiendo del alumnado de movilidad internacional asignado.

Desde el punto de vista docente, la estructura de las dos asignaturas es similar, encuadradas en unos epígrafes de trabajo. Corresponde a Proyectos 5 el epígrafe Equipamiento. De modo amplio, se entienden por tales los edificios de servicios de la comunidad. En estas asignaturas el desarrollo de los conocimientos se estructura fundamentalmente a través del ejercicio del curso, un proyecto específico a desarrollar por cada estudiante. En el enunciado se describe el lugar de intervención y el programa del edificio a proyectar. En algunos casos se proponen actividades complementarias para reforzar algún aspecto de acompañamiento al ejercicio del curso, dando unidad al conjunto de la enseñanza. En el desarrollo habitual de la asignatura, el tiempo de la docencia de destina a las correcciones públicas del ejercicio.

Las aulas utilizadas para estas asignaturas cuentan con mesas bajas para el trabajo generalmente con ordenador, por lo que la ocupación del aula está determinada por la proximidad a una toma de corriente. Normalmente en el aula no es posible mover las mesas para cambiar la configuración que permita crear un estado de relaciones adecuado a una actividad concreta, lo que supone una limitación para algunas dinámicas.

Ciclos de Mejora en el Aula (2020). Experiencias de Innovación Docente de la US Esta obra se distribuye con la licencia Creative Commons 


\section{Diseño del Ciclo de Mejora en el Aula (CIMA)}

En el diseño del CIMA se han incluido tres actividades distintas con continuidad argumental para dar sentido a una forma de trabajo con las primeras acciones del proyecto de arquitectura. En cierto modo, el ejercicio de curso para el estudiante tiene equivalencia con el encargo de un edificio o la decisión de presentarse a un concurso de arquitectura para el arquitecto: es una materia de investigación y trabajo.

\section{Mapa de contenidos y problemas clave}

La construcción del mapa de contenidos ha puesto de manifiesto que la docencia de la asignatura gira en torno al ejercicio del curso -o de los ejercicios-, el centro de la actividad que engloba todo. Formalmente, los contenidos están supeditados al desarrollo de dichos ejercicios de proyectos, formando la estructura real de la docencia. De este modo, no hay una organización y desarrollo en el tiempo de esos contenidos. Se van proponiendo a medida que se avanza en el ejercicio y a demanda de las situaciones de los proyectos desarrollados por los estudiantes. Por la práctica docente, la selección y propuesta de ejercicios abarca distintas situaciones para que se incorporen los contenidos mediante la actividad principal de la asignatura en el aula, centrada en las correcciones de proyectos, ámbito donde el estudiante expone su trabajo y recibe una revisión-corrección del profesor. Si bien esta corrección se realiza sobre la propuesta concreta de un estudiante, en general, la sesión es pública y tiene utilidad para todo el aula.

En el mapa de contenidos (figura 1) se recoge la descripción gráfica con las tres actividades de contraste propuestas para Proyectos 5 (epígrafe: equipamiento), en el Ciclos de Mejora en el Aula (2020). Experiencias de Innovación Docente de la US
Esta obra se distribuye con la licencia Creative Commons 
ámbito de la propuesta de este CIMA. Con ellas se trabajan contenidos específicos de segundo nivel de la asignatura, cuyo objetivo final será influir sobre los contenidos principales de la asignatura en el momento naciente de la idea del ejercicio de proyectos propuesto. En cada fase de trabajo o en cada sesión, los estudiantes realizan la tarea con autonomía, con unas indicaciones mínimas, teóricas o técnicas. Para ello se debe tener en cuenta que todo resultado individual es válido y su calidad está en función del planteamiento de partida, su capacidad de desarrollo y su justificación en términos disciplinares. Se incluye como contenido una competencia transversal: aptitud para ejercer la crítica arquitectónica, raíz del planteamiento de las sesiones críticas en las que se presentan los resultados, mediante la explicación de los estudiantes a sus compañeros de las ideas de trabajo o la selección realizada, expresando la motivación de las decisiones continuas a las que está sometido el proyecto de arquitectura. Estos resultados tendrán una acción directa sobre los contenidos principales de la asignatura, a través de los que se influye en el ejercicio del curso.

Ciclos de Mejora en el Aula (2020). Experiencias de Innovación Docente de la US Esta obra se distribuye con la licencia Creative Commons 


\section{ZACARÍAS DE JORGE-CRESPO}

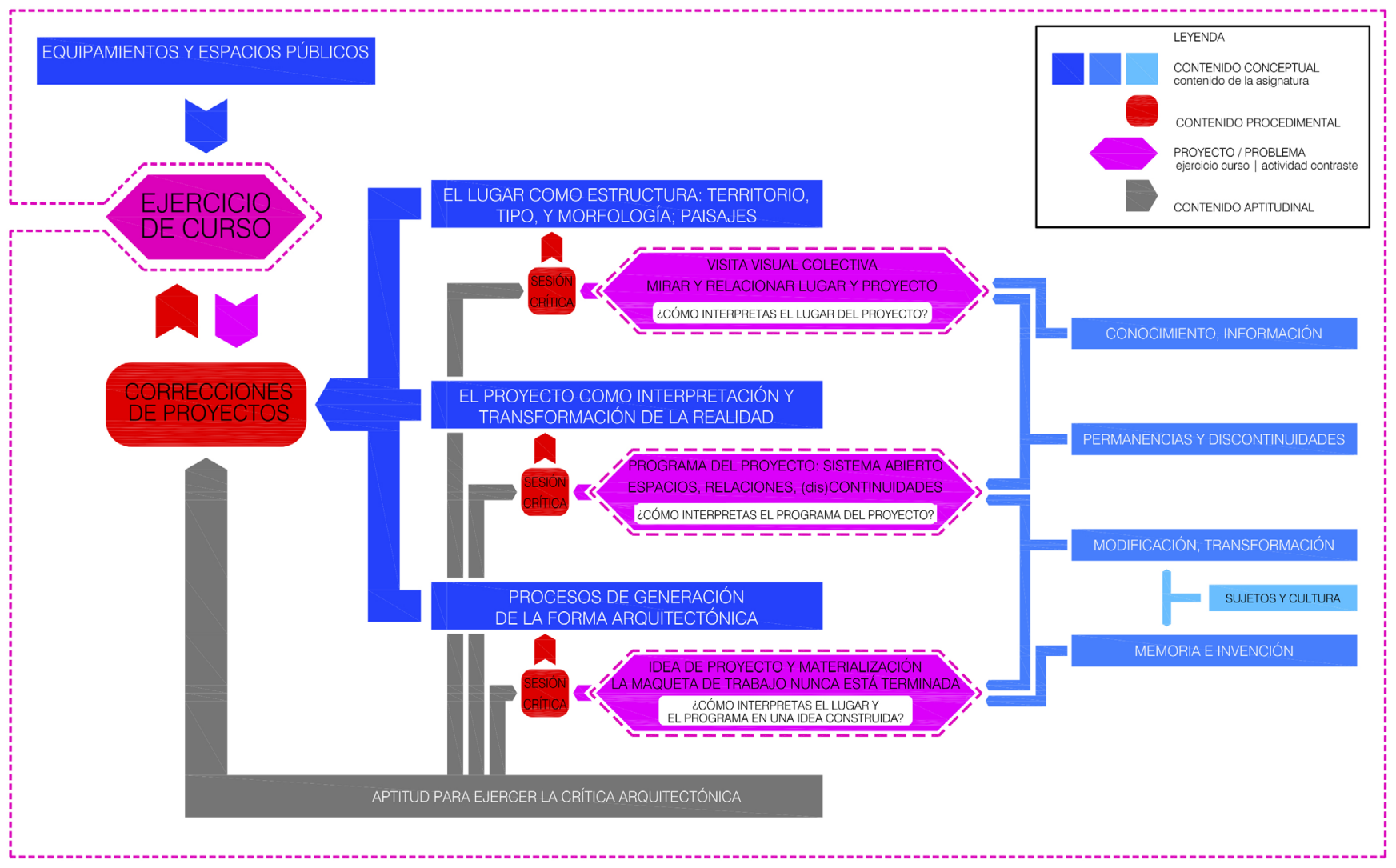

Figura 1. Mapa de contenidos para las actividades de contraste propuestas.

Ciclos de Mejora en el Aula (2020). Experiencias de Innovación Docente de la US (c) E $\Theta$ Esta obra se distribuye con la licencia Creative Commons cc) $(7) \Theta$ Reconocimiento-NoComercial-SinObraDerivada Internacional (CC BY-NC-ND 4.0.) 


\section{Problemas clave y secuencias de las actividades}

Al plantear las actividades, se recupera una reflexión propuesta en el planteamiento del primer CIMA: ¿dónde está el desafío para el estudiante? (Bain, 2007) El desafío que se propone al estudiante es el aprendizaje necesario para tomar decisiones justificadas y expresarlas. Así, la toma de decisiones en el proyecto se hace más sólida, obteniéndose mejores resultados. En estas actividades se desplaza al alumno a una posición activa.

Cada una de las actividades de contraste es una propuesta de ejercicio y servirán de apoyo al ejercicio de curso. Surgen de la intención de trabajar sobre las ideas de mirar, pensar y crear, incorporando un punto de vista del campo disciplinar del proyecto con cada una de las tres actividades de contraste. Estas se presentan buscando continuidad entre ellas, a partir de las preguntas iniciales que se proponen, todas con una parte común: ¿Cómo interpretas...? Desde el primer momento se pone de manifiesto que el proyecto no es un resultado predeterminado, si no que será el resultado de un proceso constantemente retroalimentado por la información recibida y las decisiones tomadas.

La primera actividad propuesta es la sesión crítica de cierre de la visita visual colectiva, sobre el montaje de las propuestas gráficas de cada estudiante de la visita al lugar del proyecto (figura 2). ¿Cómo interpretas el lugar del proyecto? Los objetivos con los que se realiza esta actividad son los siguientes:

- Relacionar imágenes con la expresión de ideas.

- Revisar críticamente el trabajo personal a partir de la selección de las mejores imágenes de los compañeros para aportar ideas al proyecto.

- Comprobar qué han visto y cómo han mirado un espacio urbano los compañeros de clase en el paseo conjunto. Localizar otros puntos de interés.

Ciclos de Mejora en el Aula (2020). Experiencias de Innovación Docente de la US Esta obra se distribuye con la licencia Creative Commons 
- Claves para mirar y fotografiar la ciudad: el contexto, el encuadre y el detalle. De la intuición en el manejo de la fotografía y algunas claves para mejorar la técnica.

Tabla 1. Secuencia de la actividad 1: sesión crítica de la visita visual colectiva

\begin{tabular}{|c|c|c|}
\hline & ACTIVIDAD 1 | 22 octubre 2020 | 9:00 a 11:00 + 11:30 a 12:00 h & $150 \mathrm{~min}$. \\
\hline- & $\begin{array}{l}\text { Explicación general de las actividades asociadas a un Ciclo } \\
\text { de Mejora en el Aula; sólo tenéis que seguir el ritmo de la } \\
\text { clase. }\end{array}$ & $5 \mathrm{~min}$ \\
\hline 1 & $\begin{array}{l}\text { Una pregunta: ¿Qué duele más, chocarse contra un muro de } \\
\text { hormigón o un no me gusta? Alguna respuesta rápida... }\end{array}$ & $3 \mathrm{~min}$ \\
\hline 2 & $\begin{array}{l}\text { Presentación de la actividad. Explicación de la mecánica } \\
\text { del cierre de la actividad "memoria visual colectiva" } \\
\text { desarrollada, haciendo hincapié en: } \\
\text { Objetivo 1: encontrar sugerencias para el proyecto. Cada } \\
\text { uno seleccionará dos imágenes con su título y comentario. } \\
\text { Objetivo 2: expresar el lugar. Cada uno seleccionará una } \\
\text { página completa. }\end{array}$ & $7 \mathrm{~min}$ \\
\hline 3 & $\begin{array}{l}\text { Colocación de los A3 impresos con el trabajo individual } \\
\text { presentado en una pared del aula [configuración del aula } \\
\text { para la sesión, según posibilidades derivadas de las normas } \\
\text { vigentes]. }\end{array}$ & $10 \mathrm{~min}$ \\
\hline 4 & $\begin{array}{l}\text { Revisión-selección. Como en una exposición, visualización } \\
\text { de los trabajos para preparar la selección individual y su } \\
\text { exposición justificada. }\end{array}$ & $20 \mathrm{~min}$ \\
\hline 5 & $\begin{array}{l}\text { Sesión crítica. Los estudiantes, uno a uno, comentará su } \\
\text { selección: dos imágenes sueltas y una página completa. } \\
\text { Posibilidad de intervención de los compañeros de clase } \\
\text { para entablar un debate. }\end{array}$ & $75 \mathrm{~min}$ \\
\hline- & Descanso. Se organizará el póster provisional de la actividad & $30 \mathrm{~min}$ \\
\hline 6 & $\begin{array}{l}\text { Una Lectura de Proyectos: C. Kent \& J. Steward (1992) Looking. } \\
\text { 1. Ejercicio del ojo que lo ve todo: ¿es el arquitecto alguien } \\
\text { que tropieza? La mirada como experiencia del lugar. } \\
\text { 2. Importancia del encuadre: finder. } \\
\text { 3. Recapitulación para incorporar la técnica a la fotografía } \\
\text { de arquitectura. }\end{array}$ & $20 \mathrm{~min}$ \\
\hline
\end{tabular}

Ciclos de Mejora en el Aula (2020). Experiencias de Innovación Docente de la US Esta obra se distribuye con la licencia Creative Commons Reconocimiento-NoComercial-SinObraDerivada Internacional (CC BY-NC-ND 4.0.) 
7 Conclusiones / Feedback de la actividad: ¿cómo hacer que la 10 min visita al lugar del proyecto no sea un paseo sin más que una mañana dando un paseo urbano?

1. Una forma de mirar.

2. PRESENTACIÓN DEL PÓSTER: ¿ES necesario revisitar el lugar? Una reflexión sobre la exposición Un viaje a Passaic de Robert Smithson.

Debate de cierre / Volver a la pregunta inicial...

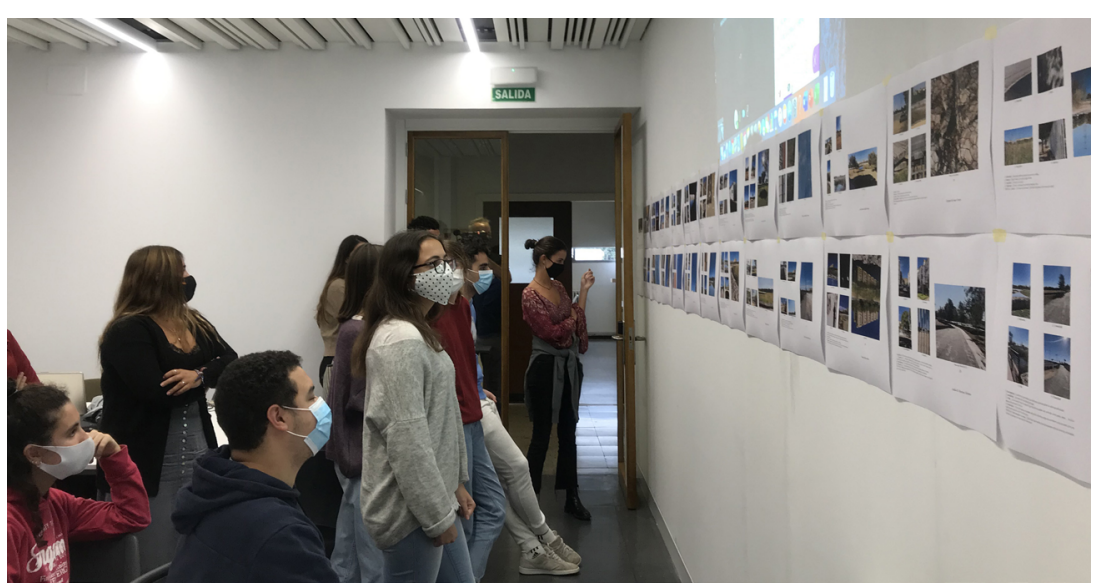

Figura 2. Visita visual colectiva. Repaso a una exposición.

A lo largo de toda la actividad -visita, fotografías y selección de imágenes-, el trabajo de los estudiantes es autónomo, salvo las indicaciones dadas para conseguir que la presentación en la maqueta prevista sea viable. Los resultados se recogen en un póster resumen con lo más destacado en la sesión, que se coloca en el aula.

¿Cómo interpretas el programa del proyecto? Esta segunda actividad, llamada el programa del proyecto es un sistema abierto, se propone trabajar en el proyecto desde el momento inicial, mediante la construcción de un programa coherente a desarrollar en el edificio y su capacidad para describir el espacio como hecho arquitectónico. Para ello, en el enunciado del proyecto se ha dejado el programa con bastantes indefiniciones y se parte del título del ejercicio. Esta propuesta es una reflexión en continuidad con Ciclos de Mejora en el Aula (2020). Experiencias de Innovación Docente de la US Reconocimiento-NoComercial-SinObraDerivada Internacional (CC BY-NC-ND 4.0.) 
la experiencia docente que narra Louis Kahn (2003), donde propone construir la idea del ejercicio de proyectos a partir del establecimiento de las relaciones internas como necesidad del proyecto propuesto.

El programa de un proyecto -y del ejercicio- habitualmente es algo dado desde el exterior. Se trata de comprender el encargo desde su raíz para construir el programa de un proyecto a partir de ese punto, desde la valoración crítica donde haya cabida para la selección y el descarte del programa. Ordenando estas ideas, estos son los objetivos de la actividad:

- Dar continuidad al análisis del lugar y extenderlo al análisis del proyecto propuesto.

- Proponer necesidades a partir de la experiencia y el conocimiento de edificios o actividades similares. Obtener como resultado el programa del ejercicio a desarrollar.

- Conectar programa con espacios.

Tabla 2. Secuencia de la actividad 2: el programa del proyecto es un sistema abierto

\begin{tabular}{lll}
\hline & \multicolumn{1}{c}{ ACTIVIDAD 2 | 22 octubre 2020 | 12:00 a 13:30 h } & $90 \mathrm{~min}$. \\
\hline 1 & $\begin{array}{l}\text { Presentación: ¿Qué os parece el programa del proyecto? } \\
\text { Objetivo: concluir el programa de necesidades (de la Sota: } \\
\text { dar liebre por gato) }\end{array}$ & $10 \mathrm{~min}$ \\
\hline 2 & $\begin{array}{l}\text { Sesión crítica } \\
\text { Los estudiantes, uno a uno, comentarán algún aspecto a } \\
\text { tener en cuenta, conectando con la intervención de los } \\
\text { compañeros para entablar un debate. }\end{array}$ & $65 \mathrm{~min}$ \\
\hline 3 & $\begin{array}{l}\text { Conclusión y resultado: completar el programa del } \\
\text { proyecto. }\end{array}$ & $15 \mathrm{~min}$ \\
\hline
\end{tabular}

Se vuelven a conectar a los contenidos varios conceptos disciplinares como lugar, proyecto, programa, espacio y experiencia, donde los estudiantes tienen que proponer una reflexión para hacer que las dependencias del programa sean espacios conectados a través de una nube de

Ciclos de Mejora en el Aula (2020). Experiencias de Innovación Docente de la US Esta obra se distribuye con la licencia Creative Commons 
relaciones internas y con el mundo que se ordena en el proyecto de arquitectura.

Por último, una maqueta de trabajo nunca está terminada es la actividad de contraste de cierre de este comienzo, en la que se propone una síntesis con la pregunta sobre cómo se interpreta el lugar y el programa del proyecto en una idea construida.

La investigación que se propone trata de dar una respuesta justificada a cada decisión de proyecto, donde la modificación de una parte afecta al todo, por lo que es muy importante la retroalimentación de este conocimiento abierto. La maqueta de trabajo de ejecución rápida permite verificar la adecuación de la solución propuesta. Con esta actividad se persiguen estos objetivos:

- Activar el inicio del proyecto. La maqueta es un resultado real y tangible.

- Encontrar y expresar una idea de proyecto de modo rápido y eficaz.

- Aplicar como herramienta de trabajo la fotografía.

- Incentivar el trabajo en el aula y la interacción entre los estudiantes: préstamos de materiales y técnicas de maquetas (salvando las limitaciones COVID).

- Obtener un resultado visible de la sesión de trabajo: póster.

Tabla 3. Secuencia de la actividad 3: una maqueta de trabajo nunca está terminada

\begin{tabular}{llr}
\hline \multicolumn{1}{c}{ ACTIVIDAD 3 | 29 octubre 2020 | 9:00 a 13:30 h } & $360 \mathrm{~min}$ \\
\hline 1 Presentación: ¿Podríais hoy terminar el proyecto del curso? & $10 \mathrm{~min}$ \\
Objetivos: idea, maqueta y fotografia. Los estudiantes \\
trabajarán individualmente (no se puede trabajar en parejas \\
por las limitaciones Covid). \\
2 Preparación de la maqueta y revisión continua por las \\
$\begin{array}{l}\text { mesas, comentando idea, materialidad y forma, o cómo } \\
\text { fotografiar la maqueta de trabajo en todas sus fases y el uso }\end{array}$ \\
del visor de encuadre.
\end{tabular}

Ciclos de Mejora en el Aula (2020). Experiencias de Innovación Docente de la US Esta obra se distribuye con la licencia Creative Commons Reconocimiento-NoComercial-SinObraDerivada Internacional (CC BY-NC-ND 4.0.) 


\begin{tabular}{|c|c|c|}
\hline- & Descanso. & $\begin{array}{r}{[30} \\
\min ]\end{array}$ \\
\hline 3 & $\begin{array}{l}\text { Fotografías. Tiempo para realizar las fotografías de la } \\
\text { maqueta. }\end{array}$ & $30 \mathrm{~min}$ \\
\hline 4 & $\begin{array}{l}\text { Fotografías. Póster versión aula: enviar/recibir las imágenes: } \\
204 \text { fotografías, palabra/s clave/s. }\end{array}$ & $30 \mathrm{~min}$ \\
\hline 5 & $\begin{array}{l}\text { Resultados. Presentación de resultados: sesión crítica y } \\
\text { debate. }\end{array}$ & $45 \mathrm{~min}$ \\
\hline 6 & $\begin{array}{l}\text { Resultados de las actividades del CIMA. } \\
\text { RESUMEN: Ver e interpretar el mundo con la mirada del } \\
\text { arquitecto. } \\
\text { Cuestionario final: pensad en vuestras respuestas iniciales } \\
\text { y responded con lo aprendido (espero vuestras respuestas } \\
\text { esta tarde). }\end{array}$ & $15 \mathrm{~min}$ \\
\hline S2 & $\begin{array}{l}\text { Póster: revisión, corrección [grupo de estudiantes], } \\
\text { impresión y presentación. } \\
\text { Apertura de la siguiente clase con la presentación en el } \\
\text { aula del póster y envío a los estudiantes. Se da paso a las } \\
\text { correcciones del ejercicio en la mesa (en la situación actual } \\
\text { de distancias y asistencia parcial se está ajustando el modo } \\
\text { de trabajo en el aula). }\end{array}$ & $15 \mathrm{~min}$. \\
\hline
\end{tabular}

Esta actividad de dinámica rápida es una respuesta eficaz en el tiempo acotado de la clase. Al terminar la sesión hay una solución materializada y entregarán las fotografías (fichero JPG) con las que montar un póster de ideas (selección en la figura 3), para resumir la actividad y presentar los estudiantes sus resultados en una sesión crítica de la clase.
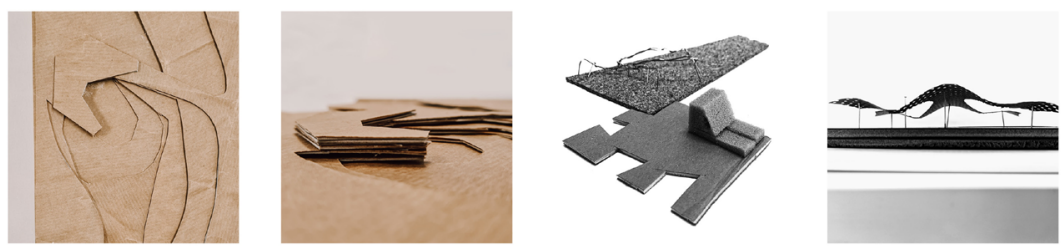

Figura 3. Una maqueta de trabajo nunca está terminada. Póster final (detalle). Estudiantes: Anna Laura Kamm, fusion [I] y fusion [II]; Marisa de Guzmán, lleno y vacío; Andrés Herrera, sombras chinescas.

Ciclos de Mejora en el Aula (2020). Experiencias de Innovación Docente de la US Esta obra se distribuye con la licencia Creative Commons 


\section{Modelo metodológico}

En el modelo metodológico de partida de la asignatura hay una fuerte carga del modelo basado en la reelaboración de las ideas de los estudiantes (de Alba y Porlán, 2017), careciendo prácticamente de actividades de contraste y basándose las sesiones críticas en el criterio del profesor. A través del ejercicio del curso, los estudiantes deben desarrollar un trabajo continuo -intelectual y de ejecución de material gráfico- para progresar con sus propuestas. Esta parte del modelo se desarrolla con las correcciones de proyectos, subrutina de trabajo en el aula donde el profesor realiza las indicaciones que entiende adecuadas a cada propuesta. Para ello se emplea la comparación de edificios, analogías, la aplicación de normativas o cualquier argumento válido para expresar las ideas arquitectónicas en un nivel más teórico, que serán recogidos en una nueva fase de trabajo del estudiante hasta la entrega final con la presentación de resultados. Sobre ese modelo global, como consecuencia de la implementación de actividades requerida por la naturaleza de este curso de innovación docente, se han incorporado a la docencia las actividades de contraste propuestas y desarrolladas en este CIMA, sobre contenidos que sirven de soporte a aspectos que refuerzan el ejercicio del curso. Las subrutinas de actividades tienen una estructura metodológica similar: propuesta del ejercicio específico sobre el que se trabajará, desarrollo individual y revisión final en el aula, con la participación de los estudiantes en la sesión crítica final. Por tanto, el modelo metodológico pone toda la carga en el trabajo del estudiante y con las actividades de contraste se refuerza su posición en el trabajo del aula y en la expresión crítica de los resultados -las intervenciones del profesor tratan de matizar o reforzar alguna intervención.

Ciclos de Mejora en el Aula (2020). Experiencias de Innovación Docente de la US Esta obra se distribuye con la licencia Creative Commons 


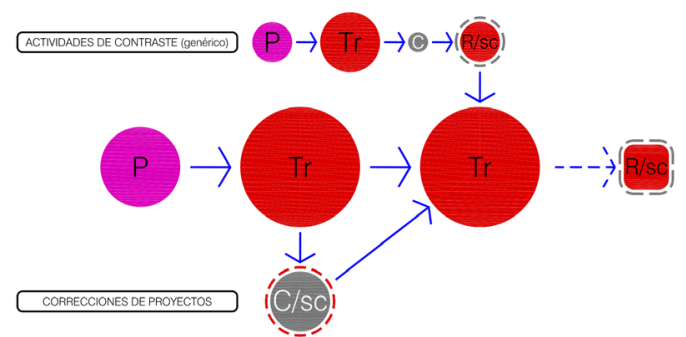

Figura 4. Modelo metodológico.
[P] Proyecto/Ejercicio (presentación) [Tr] Trabajo del estudiante

[C/sc] Corrección de proyectos (modelo sesión crítica)

[AC] Actividad de contraste [C] Corrección en aula [R/sc] Resultados (sesión crítica) [rojo] ESTUDIANTES [gris] PROFESOR [magenta] PROYECTO/PROBLEMA

\section{Cuestionario inicial y final}

En el cuestionario, tras una breve contextualización, se incluyen dos preguntas para cada una de las actividades a desarrollar, por lo que se estructura en tres partes. En la tabla 4 se desglosa el cuestionario que se pasa a los estudiantes.

Tabla 4. Cuestionario inicial y final

[1] La visita al lugar del proyecto parece que es el arranque de la actividad real del ejercicio principal de la asignatura, un día de clase relajado fuera del aula. Trata de ser algo más que un paseo por la ciudad...

1.A ¿Cómo haces de la visita al lugar una fuente útil de información? 1.B ¿Te sirve para interpretar el lugar del proyecto? [Explicar]

[2] Sólo me han dado dos condiciones básicas para el edificio: título y ocupación. Y soy yo quien tiene que decir cómo ocupar el edificio con actividades, decidir qué hacer, pero...

2.A ¿Qué haces para comprender y completar el programa del proyecto?

2.B ¿Te resulta útil el programa del proyecto para tu propuesta? [Explicar]

[3] El encargo de un edificio depende de una respuesta rápida. Tengo cuatro horas para presentar una solución viable ...

3.A ¿Cómo harías el proyecto en 4 horas?

3.B ¿Qué herramientas tienes y utilizas para construir una idea de proyecto?

Ciclos de Mejora en el Aula (2020). Experiencias de Innovación Docente de la US Esta obra se distribuye con la licencia Creative Commons 
Se garantiza el anonimato de las respuestas con un pseudónimo que emplearán en los dos cuestionarios. Responden 24 estudiantes de los 29 que forman el grupo, tanto en la fase inicial como en la fase final. Sobre el cuestionario se hacen estas observaciones:

- Las actividades matizan las respuestas dadas en el cuestionario final, siendo más precisas. Ahora bien, como se ha explicado en el caso específico de la asignatura, el mapa de contenidos pone en valor el ejercicio de proyectos como eje de la docencia y los contenidos surgen como explicación de las correcciones del ejercicio, no tratándose de un conocimiento enfocado a conseguir un resultado concreto y correcto, ya que el ejercicio propuesto es abierto -sin predeterminación de su resultado.

- A la vista del análisis de los resultados, la segunda pregunta formulada en cada uno de los tres apartados debía ser la primera, y ninguna de ellas sirve para el objetivo de una evaluación del cambio del modelo mental de los estudiantes. Por tanto, sólo formarán parte del análisis de resultados las primeras preguntas de cada actividad.

Por otro lado, se observa que por la forma de relación que se producen en las correcciones del ejercicio, la propia presentación del estudiante -la propuesta del ejercicio junto con la expresión gráfica y su expresión oral- funciona como respuestas a este cuestionario y dan una aproximación sobre la posición que tiene cada estudiante en la escalera de aprendizaje.

Ciclos de Mejora en el Aula (2020). Experiencias de Innovación Docente de la US Esta obra se distribuye con la licencia Creative Commons 


\section{Aplicación del CIMA}

\section{El desarrollo de las sesiones}

En general, todas las sesiones han sido estresantes como resultan las clases filtradas por el condicionante de la conexión para participar en línea. Lo más complicado y peor gestionado ha sido del tiempo de la secuencia, agravado por la condición coyuntural de tener a los estudiantes divididos (presencial y en sincronía). Pero cuando se ven los resultados materiales que han producido los estudiantes, la sensación final de satisfacción compensa el trabajo realizado para desarrollar las actividades del aula.

En la primera actividad, la sesión crítica sobre la visita visual colectiva capta la atención de los estudiantes con la propia exposición (figura 2), sorprendidos al ver cómo quedan sus fotografías. Tras la breve introducción, se da tiempo para elegir dos fotos individuales y una página completa del conjunto expuesto, para expresar "lo que me ha interesado" y no "lo que he hecho"; en la presentación individual justifican su elección. Al estar la clase dividida se pierde espontaneidad, interacción y dinamismo entre los estudiantes a la hora de revisar y comentar entre ellos las fotografías y en el momento de expresar con más cercanía su elección. Para terminar, les expliqué el trabajo de montaje, incidiendo en la búsqueda de ideas para el proyecto más que en la belleza de las fotografías. Una conclusión es aprender a encontrar más de lo que está a la vista, capas de información que no deben pasar desapercibidas.

En la mecánica de la actividad el programa del proyecto es un sistema abierto se ha trabajado con el recurso de pregunta y respuesta. En la explicación inicial se les plantea que el enunciado saldrá de lo que propongan. Hay muchas dudas por su parte y, para evitar los tiempos

Ciclos de Mejora en el Aula (2020). Experiencias de Innovación Docente de la US Esta obra se distribuye con la licencia Creative Commons 
muertos, no hay un orden de las intervenciones como se había previsto. Se busca dinamismo y vale cualquier respuesta para continuar. Durante algo más de una hora se construye el programa del ejercicio. Para terminar, con una breve explicación teórica se pone en relación el programa con una imagen espacial previa, así como el trabajo con la planta y la sección a un tiempo. Se conecta con la tercera actividad de este CIMA, donde expresar una idea inicial de trabajo con la premisa explicada del programa y los espacios construidos.

La última actividad surge de una pregunta: ¿seríais capaces de terminar un proyecto en cuatro horas? Las respuestas van desde imposible hasta quien lo imagina posible. Tras una breve introducción con una presentación en pantalla de un ejemplo, la actividad en el aula se vuelve frenética: el tiempo límite para hacer la maqueta termina cuando se haga el descanso. Hoy el grupo está completo en presencial con ausencias obligadas por el protocolo COVID.

La maqueta es la mediación en el aprendizaje. Se trata de un objeto en construcción: es más importante el proceso que el resultado, comprobando y corrigiendo para ver físicamente lo que proyectamos y verificar qué hacemos a través de la fotografía. Se les propone cómo modificar la realidad con lo poco que tenemos a mano: destrucción y recomposición, las características que tiene el material para trabajar y representar la abstracción de la maqueta, la acción directa sobre la idea que se quiere transmitir, puntos de vista para fotografiar la maqueta, el resultado de la imagen. Algunos empiezan a comprender la dimensión del trabajo: conectar todo lo que forma y da forma a un proyecto. Se reconduce la sesión crítica y el final de la clase con la presentación del póster. Los estudiantes ven un resultado concreto con incredulidad: es posible con pocos medios expresar una idea de proyecto. En cuatro horas Ciclos de Mejora en el Aula (2020). Experiencias de Innovación Docente de la US
Esta obra se distribuye con la licencia Creative Commons 
no se trataba de un hacer como documento acabado, sino de un hacer intelectual donde todas las piezas del proyecto pueden encajarse sí y sólo sí hay una comprensión global de todos los elementos que lo forman. Con la maqueta de trabajo se ordenan lugar, programa, relaciones y espacios en un solo acto comprensivo. La semana siguiente, con el póster terminado (figura 3), realizamos la sesión crítica real, donde los estudiantes expusieron brevemente su intención de trabajo, completando la actividad y conectando con las correcciones del proyecto.

\section{Evaluación del aprendizaje}

La evaluación de los resultados se realiza con escaleras de aprendizaje. Se incluyen las que corresponden a las preguntas indicadas (tablas 5, 6 y 7). Las dificultades expresan una justificación de la estimación de la calificación proyección de la calificación al inicio del proceso- o de la calificación final del estudiante.

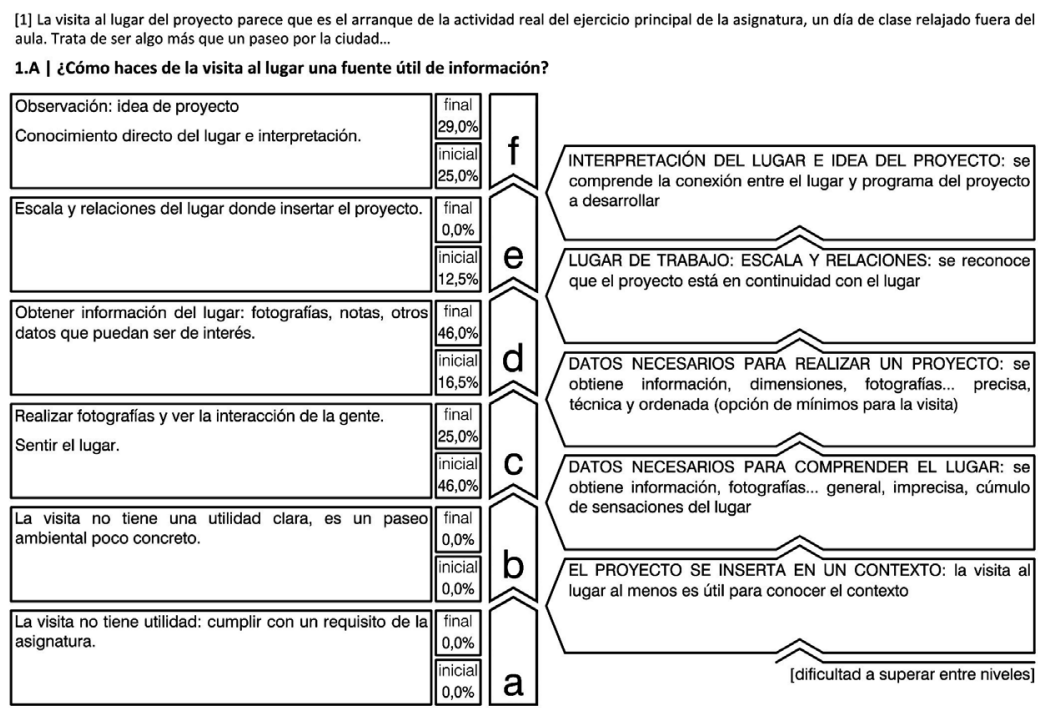

Tabla 5. Escalera de aprendizaje de la pregunta 1.A del cuestionario

Ciclos de Mejora en el Aula (2020). Experiencias de Innovación Docente de la US Esta obra se distribuye con la licencia Creative Commons Reconocimiento-NoComercial-SinObraDerivada Internacional (CC BY-NC-ND 4.0.) 


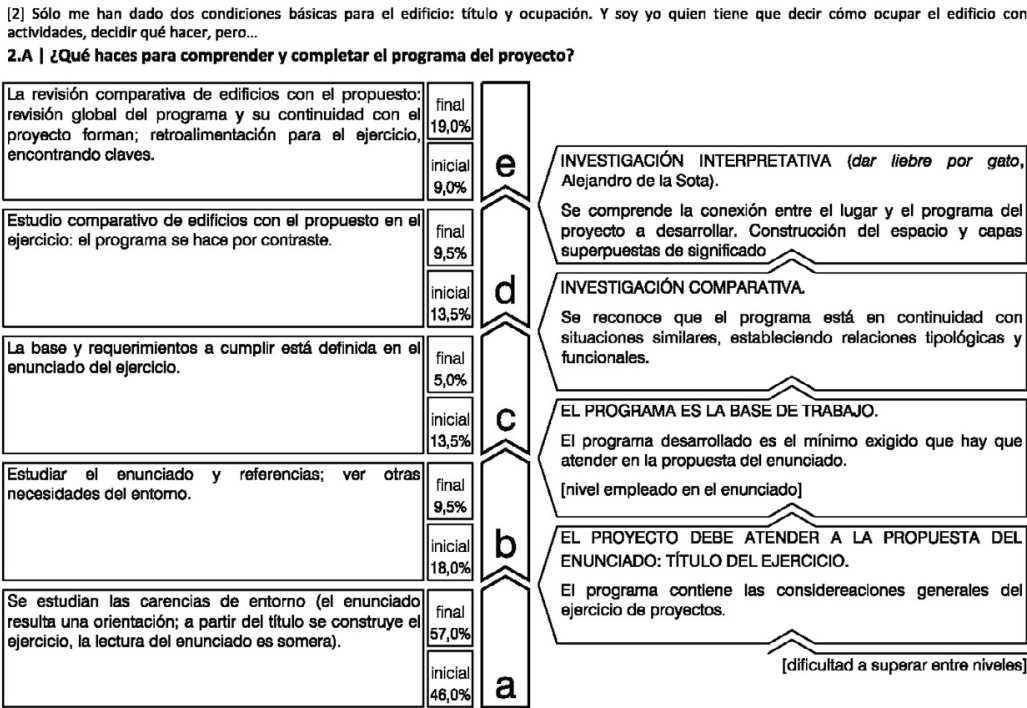

Tabla 6. Escalera de aprendizaje de la pregunta 2.A del cuestionario

[3] El encargo de un edificio depende de una respuesta rápida. Tengo cuatro horas para presentar una solución viable ... 3.A | zCómo harías el proyecto en 4 horas?

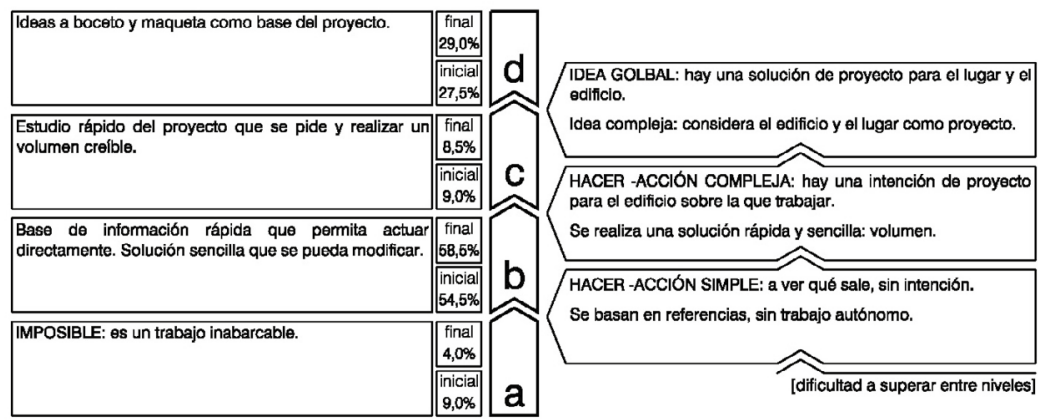

Tabla 7. Escalera de aprendizaje de la pregunta 3.A del cuestionario

El modelo de representación asimila las ideas de ascensión y dificultad, con plantas superpuestas, con un ascensor intermedio que indica los niveles, describiendo a medias plantas (parte derecha) la dificultad que se ha de superar entre niveles. Se ha incluido una proyección de respuestas no dadas, particularmente en la parte baja de la tabla para ofrecer un sentido completo a todas las situaciones posibles, basadas en la experiencia docente de la

Ciclos de Mejora en el Aula (2020). Experiencias de Innovación Docente de la US CC Esta obra se distribuye con la licencia Creative Commons Reconocimiento-NoComercial-SinObraDerivada 
asignatura. Esta transcripción responde a ideas de trabajo acumuladas, complementarias a la idea que dan los estudiantes de sí mismos con su trabajo y manera de expresarse.

Con los resultados de los cuestionarios se corrobora el mal funcionamiento ya observado en la segunda actividad de contraste. En las otras dos actividades, se produce una mejora en las respuestas dadas. Es significativo que los resultados materiales de cada actividad indican que se ha producido una transformación en el modo de afrontar el ejercicio de proyectos más intensa que las respuestas. Así mismo, las escaleras de aprendizaje muestran una actitud ante el proyecto de arquitectura y la capacidad de búsqueda e investigación cuando el estudiante se enfrenta al ejercicio de proyectos, especialmente claro en la escalera de la segunda pregunta.

\section{Evaluación del CIMA}

\section{Consideraciones para un nuevo ciclo de mejora}

En la aplicación de las actividades de contraste, los resultados materializados se valoran positivamente. La valoración de los estudiantes incide en el modo de afrontar el inicio del proyecto, haciendo referencia específica a la ayuda que les ha supuesto para empezar el ejercicio, la potenciación de la creatividad, cómo han comprendido el lugar y el espacio del proyecto y aprender de las propuestas de los compañeros, siendo todos objetivos de fondo de estas actividades. Han observado que cuando empiezan a proyectar ya no hay un papel en blanco. Es fundamental la conexión e implicación de los estudiantes con las actividades para que ellos consigan los objetivos propuestos y perfeccionen su capacidad de expresión pública.

Ciclos de Mejora en el Aula (2020). Experiencias de Innovación Docente de la US Esta obra se distribuye con la licencia Creative Commons 
De acuerdo con lo que explica Parcerisa (2005), se ha comprendido que la estructura de cada actividad está formada por la presentación, el desarrollo (dinámica de trabajo de los estudiantes) y entrega-finalización de la actividad con una conclusión. Se ha puesto especial interés en esta fase final para fijar la memoria, empleándose la sesión crítica de cierre con la participación activa de los estudiantes y el póster final con el que dejar un resumen visual.

Es evidente que es necesario realizar ajustes sobre estas actividades. En parte no ha ayudado a su desarrollo la situación de una clase partida (presencial y sincronía), pero esto ha hecho más visibles los errores de planteamiento y del funcionamiento de las dinámicas. También es necesario intervenir sobre el calendario general para ajustar estas actividades tanto en sus fases internas como en la proyección de una idea global de desarrollo del curso. De otro modo, parece que son actividades esporádicas sin un orden en relación con todo el trabajo y actividades parciales previstas de apoyo al ejercicio de curso. Este aspecto precisa de una explicación inicial para dar coherencia a las muchas actividades, conceptos e ideas - un modo de trabajo de un arquitecto- que se proponen en tan corto período a los estudiantes.

De modo más detallado, la actividad sobre el programa del proyecto necesita una reformulación completa de la dinámica del aula, mientras que las otras dos precisan ajustes temporales y de desarrollo de la dinámica. También habría que hacer ajustes en la secuencia de actividades para incluir alguna intervención breve para explicar algún concepto o alguna cuestión de técnica de la tarea en ejecución.

Ciclos de Mejora en el Aula (2020). Experiencias de Innovación Docente de la US Esta obra se distribuye con la licencia Creative Commons 
Incorporaciones de la experiencia a la práctica docente

La incorporación de las actividades de contraste como apoyo del ejercicio de curso abre posibilidades para dar sentido a la evaluación continua que en la tradición de las asignaturas que son responsabilidad del Departamento de Proyectos Arquitectónicos ha imperado y está recogido en los programas de las asignaturas. Las tres experiencias desarrolladas formarán parte de la actividad del curso de Proyectos en el grupo en el que imparta docencia, con las adaptaciones y correcciones observadas. Se han estudiado otras actividades de contraste que pueden incorporarse a la estructura del curso, como un diario con una entrada semanal, donde expresar los avances o descubrimientos útiles para el ejercicio, siendo otra la revisión analítica de arquitecturas proyectadas o construidas, fuentes que trasciendan la imagen.

En el trasfondo de estas propuestas hay un objetivo actitudinal para cambiar el modelo del significado del proyecto de arquitectura, desde su posición actual de estudiantes y que influirá en la forma de afrontar la actividad profesional. Todas estas actividades paralelas, que serán un refuerzo del trabajo en la evaluación continua, tratan de ser una introspección para los estudiantes: buscar, reflexionar y hacer por ellos mismos.

\section{Principios didácticos de la experiencia docente. Permanencias}

Todo se puede mejorar, si sabes qué y cómo. No sé a quién se puede asignar la autoría de este principio, pero es el motor para el cambio. Comprender que la docencia está formada por la relación entre contenidos, metodología y evaluación, conceptos a los que nos enfrentamos al rellenar el proyecto docente de las asignatura impartidas sin saber el alcance que tienen, es un hallazgo. A

Ciclos de Mejora en el Aula (2020). Experiencias de Innovación Docente de la US Esta obra se distribuye con la licencia Creative Commons 
partir de ese conocimiento, es fácil afrontar no ya cambios en el aula, sino en el conjunto de la docencia. Cuando se comprende el fondo, la innovación -el cambio- es la consecuencia directa: nada es como antes. Después de este proceso de introspección y reconexión de conceptos, lo que nace es una actitud, si cabe, una actitud crítica abierta para comprender la docencia en toda su extensión e intervenir sobre ella.

En el apartado de contenidos, la naturaleza y el proceder disciplinar en las asignaturas de Proyectos permite hacer el mapa de una vez para todo el curso, ordenando los contenidos con las preguntas que servirán para dar sentido al trabajo específico sobre conceptos mediante las actividades de contraste. Con ello se evita la monotonía de las clases de correcciones de proyectos, que en el fondo hace que todas las clases sean iguales.

La dinámica del aula de proyectos necesita de la aportación de los estudiantes para activarse, al menos, con su trabajo y traslado a las correcciones del ejercicio. Ahora bien, el campo de sus aportaciones se ha de extender con constancia y las actividades realizadas y descritas formarán parte de la docencia. Se realizarán otras incorporaciones para romper el modelo del estudiante-espectador que observa en clase con activaciones sencillas: haz algo y justificalo (trabajo individual) o con actividades de contraste breves, convirtiendo una pregunta cualquiera en propuesta de breve discusión en grupos y puesta en común.

Por último, la evaluación va más allá de una calificación. Verificar los resultados de la docencia incluye la revisión crítica de todo el proceso, que permita comprender todo el panorama para reajustar las ideas, propuestas, desarrollo y resultados. $Y$ todo ello engranado para que los estudiantes sean los actores de su aprendizaje.

Ciclos de Mejora en el Aula (2020). Experiencias de Innovación Docente de la US Esta obra se distribuye con la licencia Creative Commons 
Palabras clave: Proyectos 5, Grado en Fundamentos de Arquitectura, docencia universitaria, experimentación docente universitaria, crítica arquitectónica.

Keywords: Architectural Design 5, Degree in Fundamentals of Architecture, university teaching, university teaching experimentation, architectural criticism.

\section{Referencias bibliográficas}

Bain, K. (2007) Lo que hacen los mejores profesores universitarios. Valencia: Universitat de València.

De Alba, N. y Porlán, R. (2017) La metodología de enseñanza. En R. Porlán (Coord.), Enseñanza universitaria. Cómo mejorarla (pp. 37-54). San Sebastián de los Reyes: Ediciones Morata.

Kahn, L. (2003) Declaraciones sobre la arquitectura. En A. Latour (Ed.), Louis I. Kahn. Escritos, conferencias y entrevistas. El Escorial: El Croquis Editorial.

Kent, C. y Steward, J. (1992) Learning by heart: teachings to free the creative spirit. New York: Bantam Books.

Parcerisa, A. (Coord.) (2005) Materiales para la docencia universitaria: orientaciones para elaborarlos y mejorarlos. Barcelona: Octaedro.

Ciclos de Mejora en el Aula (2020). Experiencias de Innovación Docente de la US Esta obra se distribuye con la licencia Creative Commons 